\title{
Polycystic Kidney Disease
}

National Cancer Institute

\section{Source}

National Cancer Institute. Polycystic Kidney Disease. NCI Thesaurus. Code C75464.

A usually autosomal dominant and less frequently autosomal recessive genetic disorder characterized by the presence of numerous cysts in the kidneys leading to end-stage renal failure. The autosomal dominant trait is associated with abnormalities on the short arm of chromosome 16. Symptoms in patients with the autosomal dominant trait usually appear at middle age and include abdominal pain, hematuria, and high blood pressure. Patients may develop brain aneurysms and liver cysts. Patients with the autosomal recessive trait present with progressive renal failure early in life and symptoms resulting from hepatic fibrosis. The autosomal recessive trait is associated with abnormalities of chromosome 6. Polycystic kidney disease may also result as a side effect in patients on renal dialysis. 